\title{
Corrosion Behaviors of CMT Spot-Joined AA6022-T4 to Galvanized DCO3
}

\author{
Welds were investigated and compared in terms of joint morphology and \\ mechanical properties, as well as macro- and microstructure
}

\author{
BY H. Y. LEI, Y. GUO, Y. B. LI, AND B. E. CARLSON
}

\begin{abstract}
The mixed use of aluminum and steel is increasing in lightweight automotive bodies. The cold metal transfer (CMT) arc spot welding of aluminum alloy to steel has recently been developed. However, the electrochemical potential difference of dissimilar materials will inevitably degrade weld performance. Thus, this study investigated the corrosion behavior of CMT spot-welded 1-mm AA6022-T4 sheet to 1.5-mm hot dipped galvanized (HDG) low-carbon steel, DCO3. The open circuit potential (OCP) of the base materials and varying positions within the welds was measured, and the results showed that the OCP of the zinc coating on the steel substrate and zinc-rich zone at the weld root were the most negative and likely to corrode. Salt spray exposure was conducted specifically on the welds with and without e-coating. The results indicated a similar fracture mode after 20 cycles as with the as-welded condition, i.e., fracture in the weld metal, though with a slightly reduced lap-shear strength. After an exposure of 63 cycles, the weld strength decreased nearly $38 \%$, and the fracture mode transitioned to interfacial fracture due to the corroded Fe-Al IMC layer, whereas postweld e-coating of the CMT Alsteel joints provided a high level of corrosion protection.
\end{abstract}

\section{KEYWORDS}

- Aluminum • Steel $\bullet$ Zinc $\bullet$ Intermetallics $\bullet$ Welding - Corrosion

\section{Introduction}

As a means to achieve the upcoming mandated automotive greenhouse gas emissions, one lightweighting strategy for automotive body structures and closures is to use the right material in the right form for the right application (Refs. 1, 2). This strategy has resulted in a use of mixed materials, which in turn is driving joints of dissimilar materials such as aluminum to steel (Refs. 3-5).

The cold metal transfer (CMT) arc welding process is a modified gas metal arc welding (GMAW) process wherein the heat input during welding can be substantially reduced compared to the standard GMA process. Furthermore, the CMT process has been found to produce acceptable joint quality in joint welding of aluminum to steel sheets with a thin $\mathrm{Fe}-\mathrm{Al}$ IMC layer (Refs. 6, 7). However, welding distortion is an inherent issue for CMT joint welding of aluminum to steel because of differences in the thermal expansion coefficient between aluminum alloys and steel. To overcome the disadvantages of seam welding, CMT arc spot welding was proposed as a method to join aluminum alloys to galvanized steels in previous work. Three spot welding modes, i.e., direct welding (DW), plug welding (PW), and edge plug welding (EPW), were investigated (Ref. 8); the EPW mode was found capable of homogenizing the welding heat input and producing welds with a relatively thin and uniform intermetallic compound (IMC) layer, and thereby, acceptable mechanical performance (Ref. 9).

However, because of the differences in electrochemical potential within a dissimilar material joint, corrosion is a significant concern. A conventional solution for Al-steel joints is to pretreat the $\mathrm{Al}$ prior to joining and then apply adhesive along the joint as an isolation barrier and mechanically join the pretreated $\mathrm{Al}$ and zinc-coated steel using selfpiercing rivets. Unfortunately, introduction of adhesive to a fusion joint, especially a single-sided joint, can create significant issues with gas generation, which can lead to porosity and spatter. Thus, without the isolating barrier of adhesive, corrosion properties of the Al-steel joint created by the relatively new CMT arc spot welding process is of concern.

In available literature to date, there are a relatively small number of publications focusing on the corrosion mechanism and properties of dissimilar Al-steel welds. Wloka et al. studied the electrochemical behavior and macro corrosion attack of welded joint using aluminum alloy and hot-dip galvanized (HDG) steel via laser brazing with the application of different types of welding wire: $\mathrm{AlMg}_{6} \mathrm{Mn}$ and $\mathrm{ZnAl}_{2}$. Strong coupling effects at the boundary between the filler materials and steel were found, and the fusion zone of the weld was most prone to corrosion (Ref. 10). The corrosion property of the pulsed double-electrode gas metal arc (DE-GMA) weldbrazed joints of aluminum and zinc-coated steel with ER5356 and ER4043 welding wire was studied by Yu Shi et al. The results revealed that galvanic corrosion occurred in the weld, and the zinc-rich zone corroded first during immersion tests (Ref. 11). One effective method to minimize 

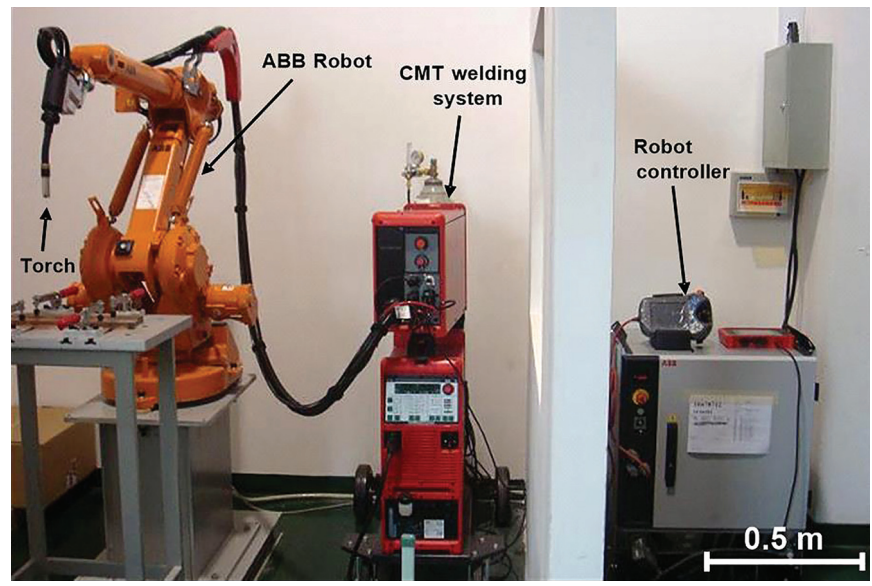

Fig. 1-The CMT welding system.

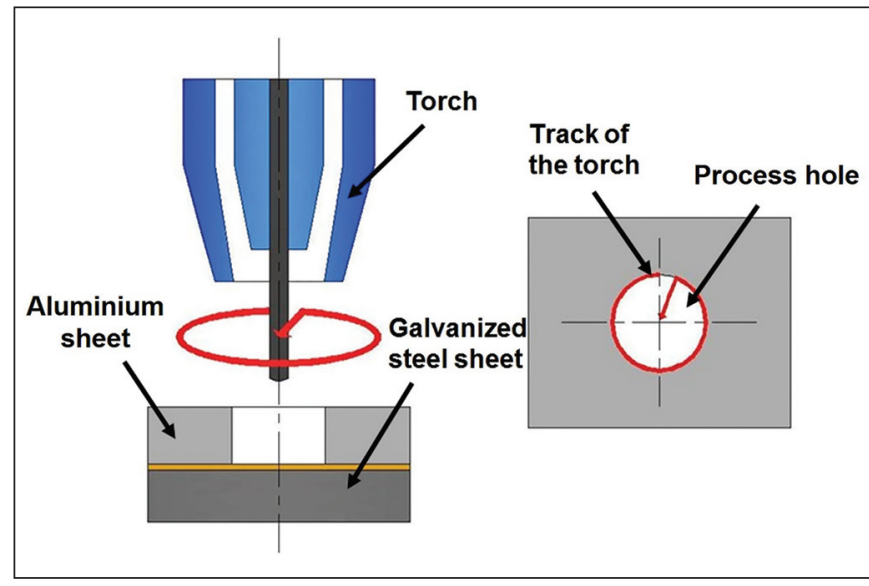

Fig. 3 - Illustration of the CMT arc spot welding process using the EPW mode.

corrosion was the application of a protective coating, which covers both the weld and the base metal (Refs. 12, 13). Alsteel CMT arc spot welds involve various types of materials, including aluminum alloy, steel, zinc coating, and filler materials, resulting in a brazed Fe-Al IMC layer. Therefore, galvanic corrosion in the multimaterial weld is highly probable.

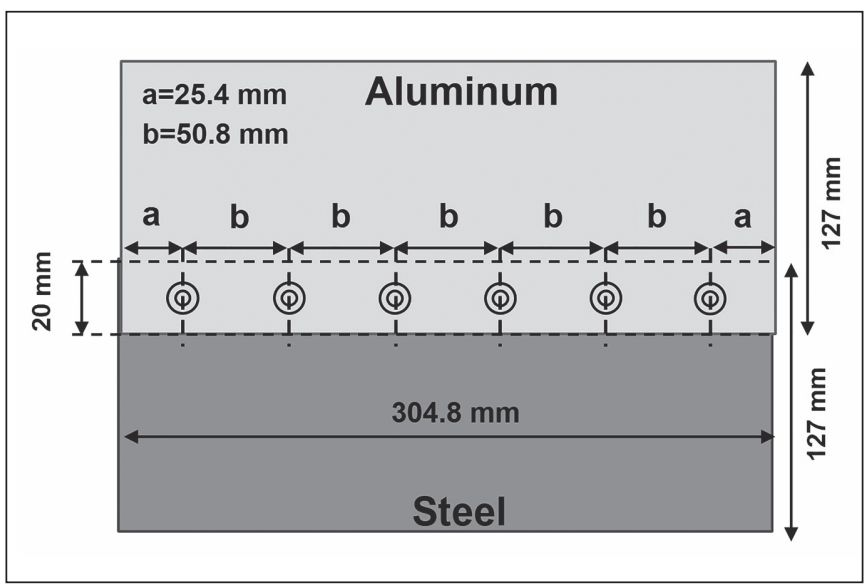

Fig. 2 - Schematic of the CMT arc spot weld positions relative to the positioning of the 1-mm AA6022 and 1.5-mm DCO3 panels.

In this study, the open circuit potential (OCP) of base materials and various locations within the $\mathrm{CMT}$ Al-steel welds were measured in addition to the accelerated salt spray exposure testing carried out on the welds in the as-welded condition as well as after e-coating. Mechanical testing of coupons having undergone environmental exposure was completed and complemented by macro- and microstructural analysis of the welds to systematically study the corrosion mechanism of the brazed aluminum-steel welds.

\section{Experimental Procedures}

\section{Welding Procedure}

The CMT arc spot welding process of aluminum to galvanized steel was carried out using a Fronius TransPuls Synergic 3200 CMT welding system integrated with an ABB IRB 1410 industry robot to control the movement of the welding torch, as shown in Fig. 1. The materials used in the study were 1-mm-thick 6022-T4 aluminum alloy and 1.5-mmthick HDG DC03. The welding wire was AlSi5 (4043) with a diameter of $1.2 \mathrm{~mm}$. The chemical compositions and nomi-

Table 1 - Chemical Compositions of AA6022-T4, 4043, and HDG DC03 (wt-\%)

\begin{tabular}{ccccccccccccccc} 
& $\mathrm{Mg}$ & $\mathrm{Si}$ & $\mathrm{Cu}$ & $\mathrm{Mn}$ & $\mathrm{Zn}$ & $\mathrm{Ti}$ & $\mathrm{C}$ & $\mathrm{S}$ & $\mathrm{P}$ & $\mathrm{Fe}$ & $\mathrm{Al}$ \\
\hline AA6022-T4 & $0.45-0.70$ & $0.8-1.5$ & $0.01-0.11$ & $0.02-0.10$ & 0.25 & 0.15 & - & - & - & $0.05-0.20$ & Bal. \\
ER4043 & $\leq 0.1$ & $\leq 5$ & $\leq 0.05$ & - & - & - & - & - & - & $\leq 0.04$ & Bal. \\
HDG DC03 & - & - & - & $\leq 0.45$ & - & - & $\leq 0.1$ & $\leq 0.035$ & $\leq 0.035$ & Bal. & $\geq 0.2$
\end{tabular}

Table 2 - Mechanical Properties of AA6022-T4 Aluminum and HDG DC03 Steel

\begin{tabular}{ccccc} 
Materials & $\begin{array}{c}\text { Yield Strength } \\
(\mathrm{MPa})\end{array}$ & $\begin{array}{c}\text { Ultimate Tensile } \\
\text { Strength (MPa) }\end{array}$ & $\begin{array}{c}\text { Elongation } \\
(\%)\end{array}$ & $\begin{array}{c}\text { Elastic Modulus } \\
(\mathrm{GPa})\end{array}$ \\
\hline AA6022-T4 & 135 & 252 & 26 & 70 \\
HDG DC03 & 210 & 350 & 37 & 206 \\
\end{tabular}



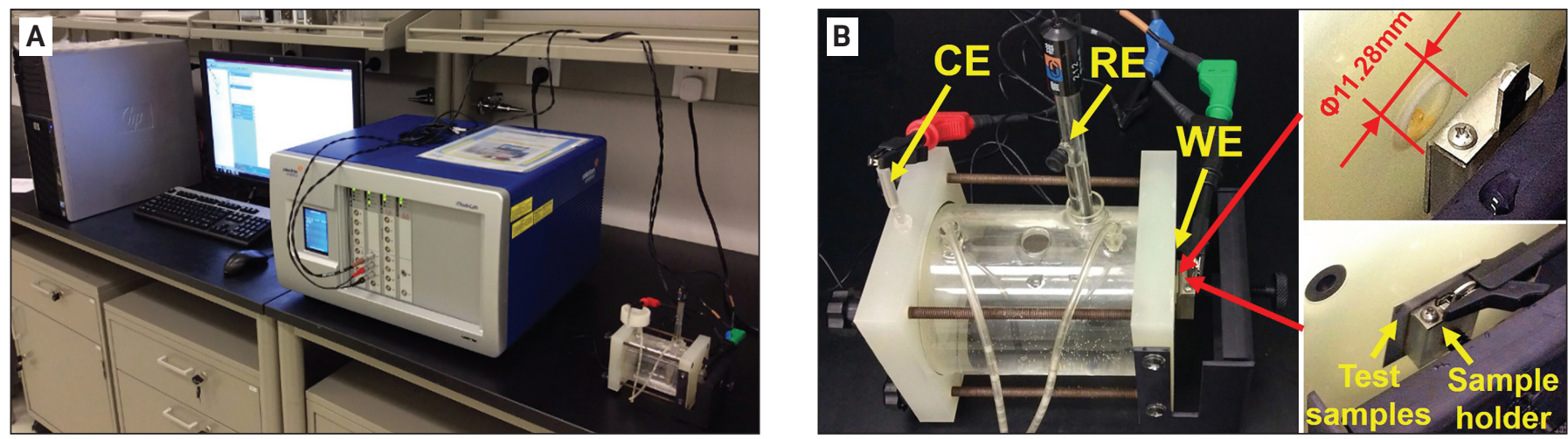

Fig. 4 - Electrochemical test workstation: A - Modulab potentiostat; B - flat cell with three electrodes.
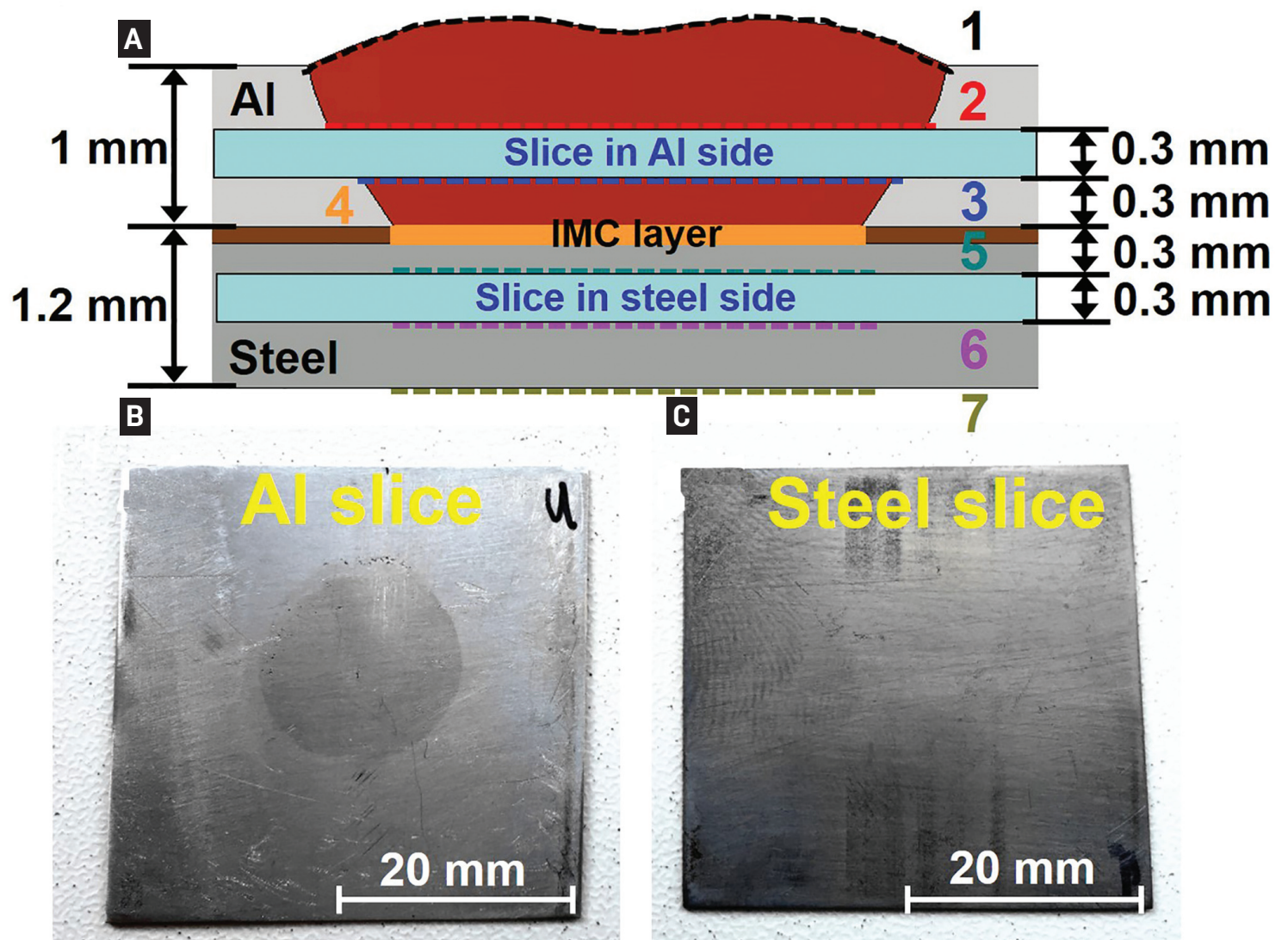

Fig. 5 - OCP testing: $A$ - Relative positions within the weld; $B$ - section through the aluminum weld; $C$ - section through the base steel substrate.

nal properties of the base materials are listed in Tables 1 and 2 , respectively. The composition of zinc coating on the steel was zinc $+0.15-0.20 \% \mathrm{Al}+0-0.1 \% \mathrm{~Pb}$ or $0-0.5 \% \mathrm{Sb}$, and the layer thickness was typically less than $10 \mu \mathrm{m}$.

The aluminum alloy and zinc-coated steel were fabricated into 304.8- $\times 127-\mathrm{mm}$ panels, and the aluminum alloy panel was positioned as the top sheet closest to the CMT torch with an overlap width of $20 \mathrm{~mm}$, as presented in Fig. 2. All the panels were cleaned using acetone to remove any surface contamination.

The EPW mode (Refs. 8, 9) (refer to Fig. 3) was adopted to spot weld aluminum alloy to galvanized steel. This process requires a predrilled hole in the top aluminum sheet. The diameter of the hole used in the study was $6.5 \mathrm{~mm}$ with a $50.8-\mathrm{mm}$ interval on the panel (refer to Fig. 2). The welding torch was kept perpendicular to the aluminum sheet with an extension of $12 \mathrm{~mm}$, and the center of the wire was aligned to the edge of the hole. The welding torch moved along the edge of the predrilled hole at a translation speed of $27 \mathrm{~mm} / \mathrm{s}$. Upon reaching an angle of $337.5 \mathrm{deg}$ from the starting position, the torch changed direction toward the center of the hole. The arc was extinguished upon reaching the center of the hole. The wire 


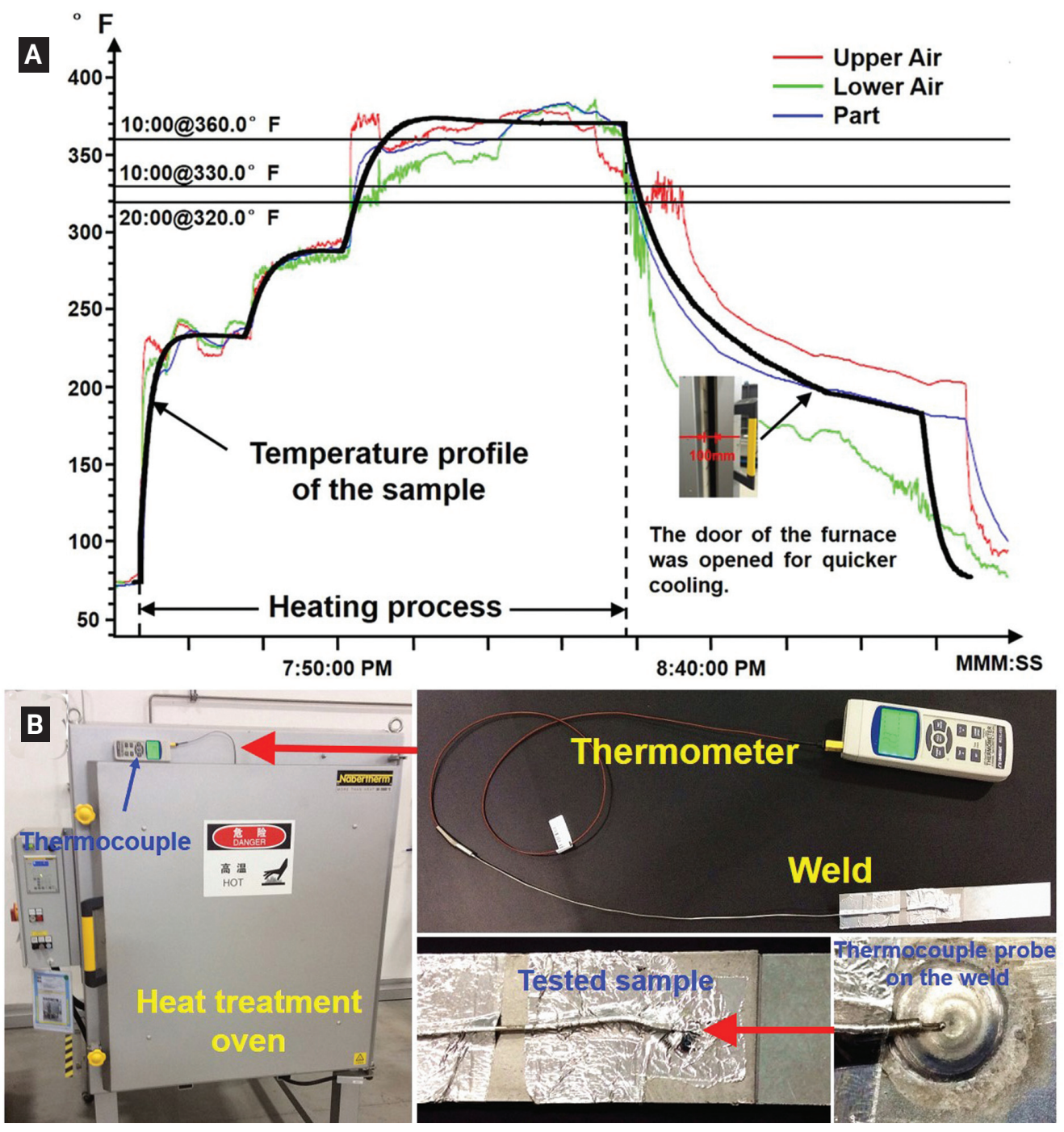

Fig. 6 - Heat treatment of non e-coated panels. A - Temperature profile used in e-coating; B - heat-treatment oven and thermocouple fastened to the welded assembly.

feed speed was $5.6 \mathrm{~m} / \mathrm{min}$, the welding current was $116 \mathrm{~A}$, and the voltage was $14.0 \mathrm{~V}$. A shielding gas of $99.999 \%$ pure argon was adopted at a flow rate of $20 \mathrm{~L} / \mathrm{min}$.

\section{Electrochemical Measurements}

The open circuit potential (OCP) measurements were taken using a Modulab potentiostat, as shown in Fig. 4A. A three-electrode PAR flat cell was employed, which used a saturated calomel reference electrode (RE) and a pure Pt-mesh counter electrode (CE). A photo of the apparatus is presented in Fig. 4B. The electrolyte was a $3.5 \% \mathrm{NaCl}$ solution. A baseline measurement of the bare steel substrate was desired. Thus, to eliminate any batch-to-batch variation, the zinccoated DC03 steel surface was ground using a 180-, 600-, and 1200-grit $\mathrm{SiC}$ abrasive paper to expose the underlying steel substrate for $\mathrm{OCP}$ measurements.

Figure 5A is a drawing of the CMT Al-steel weld with various positions in the stackup, indicating where specimens were extracted for OCP measurements. Position 1 is the top surface of the weld, and then sections were taken through the stackup until position 7 , which is the bottom surface of the zinc-coated steel. Electrical discharge machining (EDM) was used to section the weld stackup to remove slices of material, as exemplified by the two in Fig. 5B and C. The circular CMT weld can be clearly seen within the aluminum substrate material in Fig. 5B. If the steel slice in Fig. 5C were polished, it would exhibit a circular heat-affected zone because no nugget is formed within the steel. Positions 2 and 3 , which were the top and bottom surfaces of the $\mathrm{Al}$ slice, were the filler metal in the nugget on the aluminum side. The diameter of the area of filler metal was larger than the working electrode on the flat cell to make sure that only the filler metal was exposed to the electrolyte when the OCP testing was conducted. Position 4 is intended to enable OCP measurements of the IMC layer. Because of the difficulty in accurate positioning of the EDM process in relation to the very thin IMC layer, it was decided to load the weld to fracture and thereby expose the IMC layer. This had the advantage of isolating the IMC layer though introducing a certain 

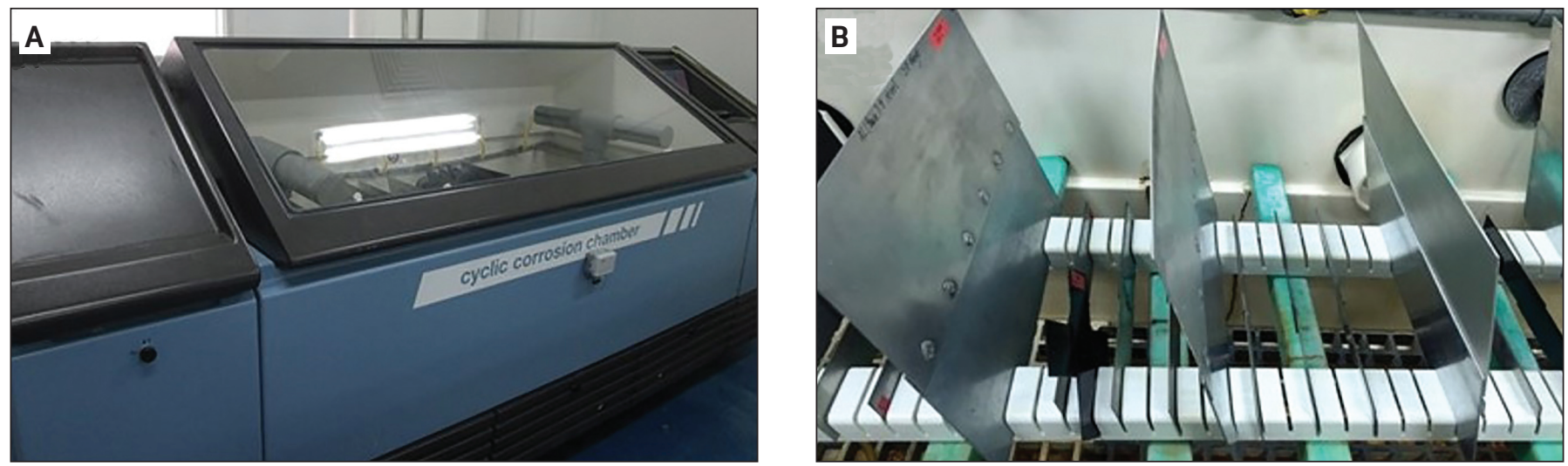

Fig. 7-Cyclic corrosion test: A - Test chamber; B - positioning of welded panels in the chamber.
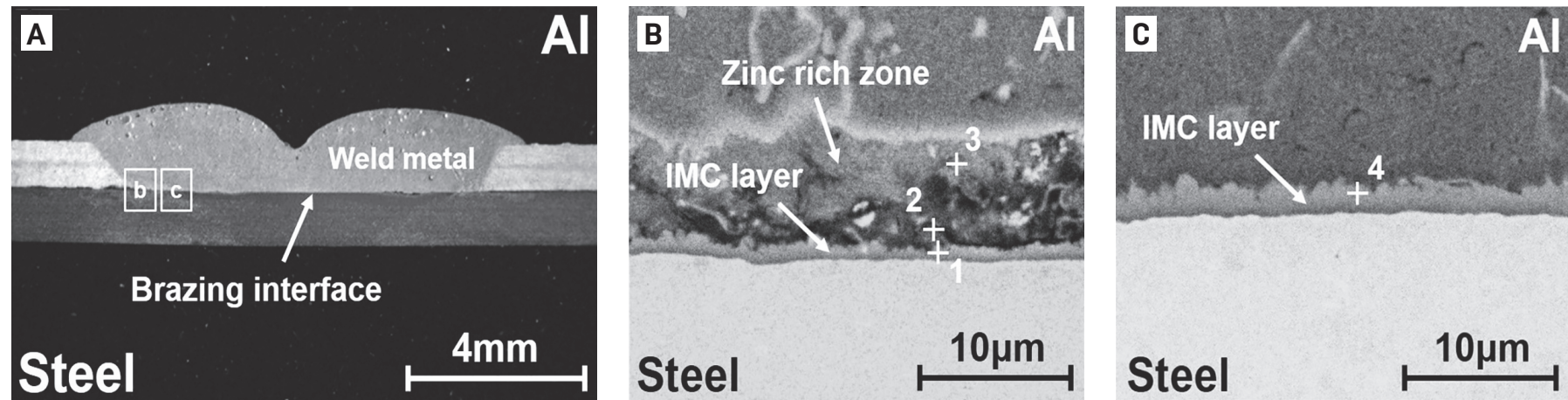

Fig. 8 - Weld morphology and microstructure: $A$ - Cross section of the weld; $B$ - enlarged view of the region $b$ presented in $A ; C$ - enlarged view of the region c presented in A (Ref. 10).
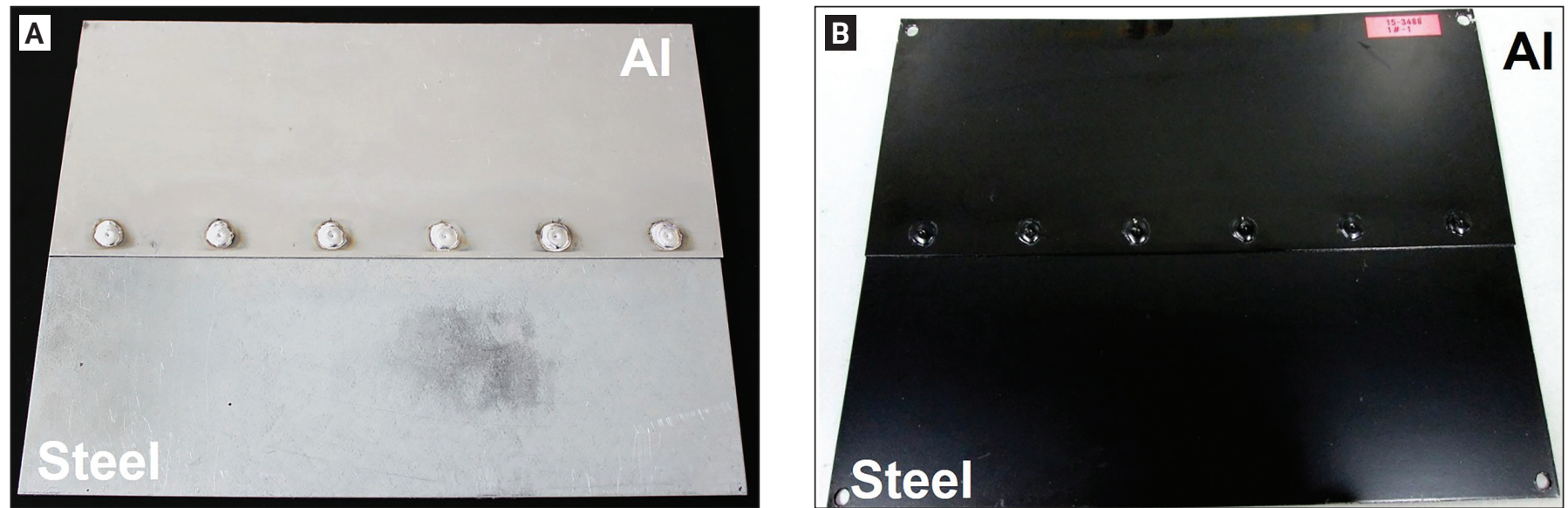

Fig. 9-Morphology of the CMT spot-welded panels: A - As-welded and without e-coating; B - e-coated following welding.

amount of surface texture, which is not consistent with the other positions. Three specimens were measured for each position.

\section{E-Coating of Samples}

An electrophoretic deposition process, e-coat, is a coating process within the automotive assembly paint process that deposits particles onto the surface of the aluminum and/or steel body in white prior to painting. As such, e-coating does provide a level of corrosion protection and, therefore, needs to be considered in the experimental plan especially for dissimilar material joints. Thus, welded panels were e-coated to simulate the industrial body in white process. However, because the e-coating process consists of immersion in a water-based solution containing paint epoxy-based emulsion followed by curing, referred to here as "paint bake," all welded panels underwent a paint bake process to eliminate any potential heat treatment effects. The maximum temperature of the bake process was about $190^{\circ} \mathrm{C}\left(375^{\circ} \mathrm{F}\right)$. The red, green, and blue plots in Fig. 6A are experimental measurements from the e-coating process with the blue plot based upon data from a thermocouple affixed to an actual welded 


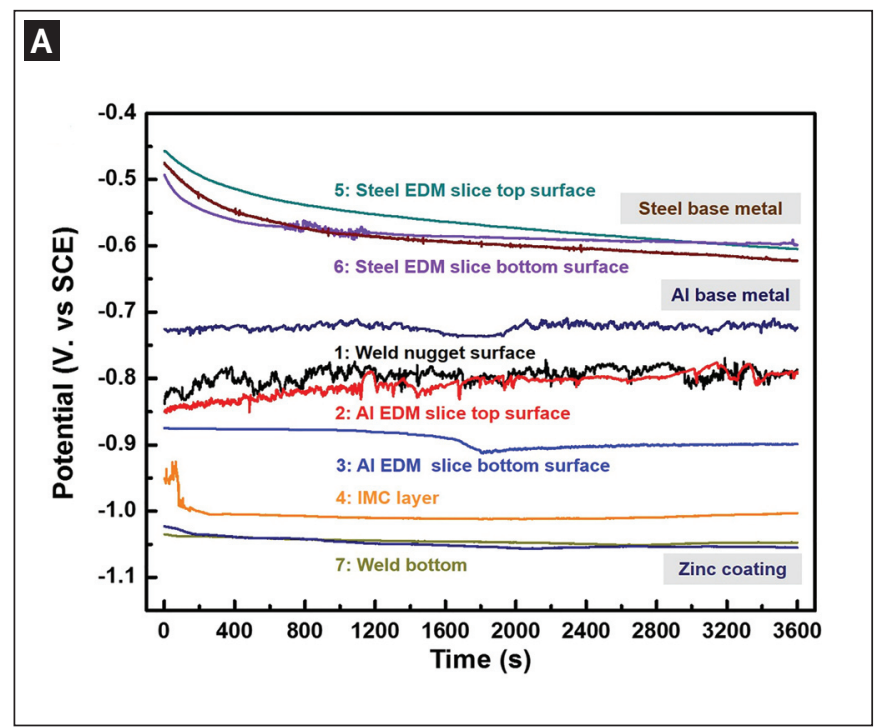

B

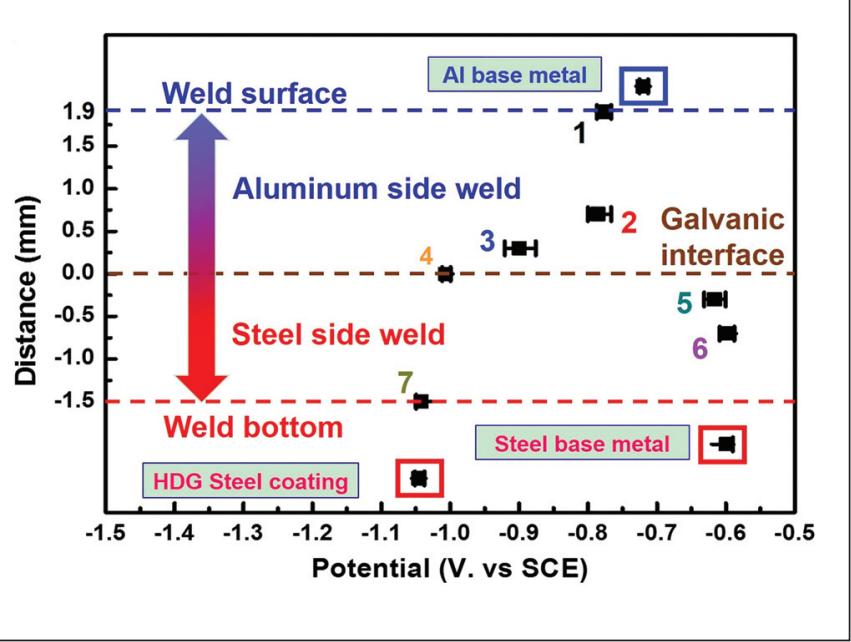

Fig. $10-O C P$ testing of the substrate and different positions of the weld: $A$ - Positions tested in the weld; B - potential curves as a function of time for various substrates and weld positions.

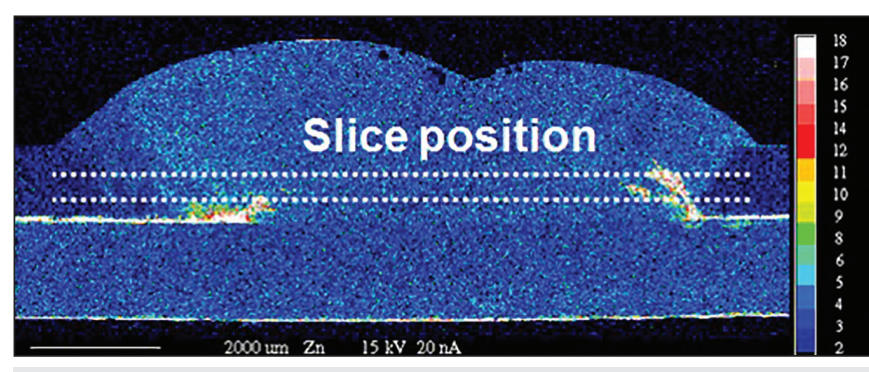

Fig. $11-$ EPMA analysis of zinc distribution within the weld.

panel assembly. This data was used to generate a heat-treatment schedule for non e-coated coupons in the furnace seen in the photo (refer to Fig. 6B). The black plot in Fig. 6A is the experimental thermal history of a non e-coated coupon affixed with a thermocouple in the furnace, which exhibits good correlation to the thermal history inherent in the ecoating process. The probe of the thermocouple was fastened on the weld surface with heat-resistant adhesive tape, as shown in Fig. 6B.

\section{Salt Spray Test}

Typical automotive environmental exposure testing employs some form of salt spray exposure. The current study followed the standard GMW14872 and carried out the testing using an auto technology cyclic corrosion test chamber. The welded panels were placed at an angle of $30 \mathrm{deg}$ to the vertical reference line with the steel sheet at the bottom (re- fer to Fig. 7). The water solution within the chamber was composed of $0.9 \% \mathrm{NaCl}, 0.1 \% \mathrm{CaCl}_{2}$, and $0.075 \% \mathrm{NaHCO}_{3}$. Because the GMW14872 was an internal standard from General Motors, the salt spray exposure cycle was listed in Table 3, which consisted of three stages, e.g., ambient, humid, and dry off (Ref. 14). Two different exposure cycles, i.e., 20 and 63 days, were adopted to investigate the influence of exposure time. Although GMW14872 stipulates a targeted mass reduction, this was not measured because the corrosion products found at the notch root are difficult to remove, and their presence would cause significant error in the mass loss measurements.

\section{Microstructural Analysis and Mechanical Testing}

Because any welded assembly would be e-coated, the greatest concern is not the top or bottom sheet surfaces but the area of the notch root where e-coating penetration may not reach and dissimilar materials of the Al-steel joint are in intimate contact. Thus, individual welds of a panel were extracted and cross sectioned to examine the effect of corrosion on weld macro- and microstructure. The weld cross sections were mounted and first ground with 180-, 600-, and 1200 -grit $\mathrm{SiC}$ abrasive paper followed by polishing with suspension liquids on a Presi polishing machine. Keller's reagent $\left(1 \mathrm{~mL} \mathrm{HF}+1.5 \mathrm{~mL} \mathrm{HCl}+2.5 \mathrm{~mL} \mathrm{HNO}_{3}+95 \mathrm{~mL}\right.$ $\mathrm{H}_{2} \mathrm{O}$ ) was used to etch the aluminum side for $15 \mathrm{~s}$, and $4 \%$ nital was used to etch the steel side for $20 \mathrm{~s}$ to highlight the

Table 3 - Salt Spray Exposure Cycle Based on GMW14872 (Ref. 14)

\begin{tabular}{cccc} 
Control Variable & Ambient Stage & Humid Stage & Dry-Off Stage \\
\hline Temperature & $25 \pm 3^{\circ} \mathrm{C}$ & $49 \pm 2^{\circ} \mathrm{C}$ & $60 \pm 2^{\circ} \mathrm{C}$ \\
Humidity & $\sim 45 \pm 10 \% \mathrm{RH}$ & $\sim 100 \% \mathrm{RH}$ & $\leq 30 \% \mathrm{RH}$ \\
Duration & $8 \mathrm{~h}$ & $8 \mathrm{~h}$ & $8 \mathrm{~h}$ \\
\hline
\end{tabular}



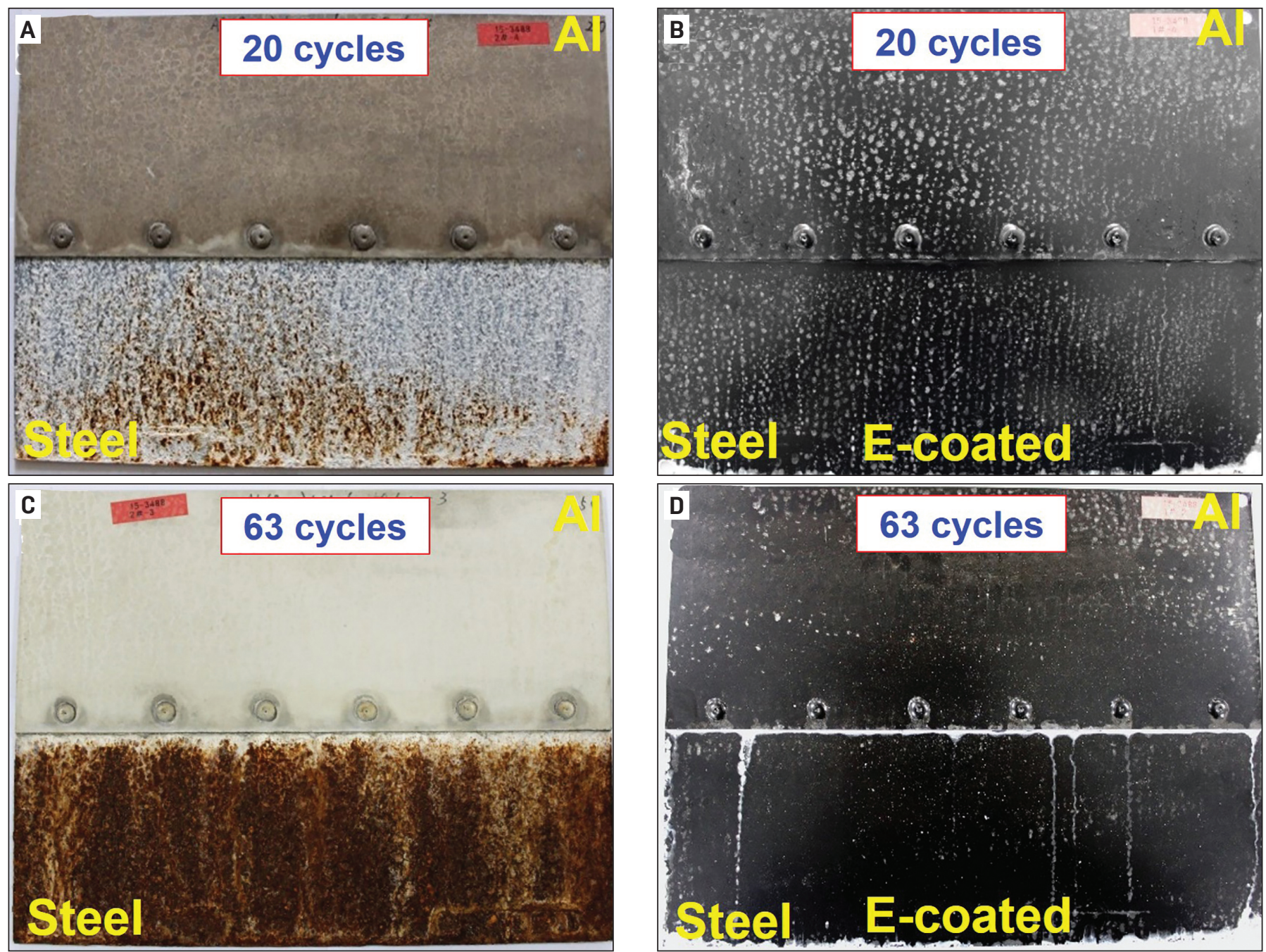

Fig. 12 - The CMT-welded Al-steel panels after salt spray exposure: A - Without e-coat after 20 cycles; B - e-coated after 20 cycles; $C$ - without e-coat after 63 cycles; $D-e$-coated following 63 cycles.

microstructure. Optical microscopy was adopted to observe the macro- and microstructure of the welds.

Finally, the effects of corrosion were measured upon the lap-shear strength of the welds. The welded panels before and after corrosion were laser cut into 38-mm-wide coupons with a single weld positioned along the centerline. Laser cutting was employed as a means to minimize any disruption of the weld joint, especially after longer cycles of environmental exposure. Quasistatic lap shear testing was conducted using a SUNS UTM5504 load frame at a loading rate of 1 $\mathrm{mm} / \mathrm{min}$. The normal fixture for lap shear test of materials was adopted for tensile testing of the weld. Backing plates were placed at both ends of the welded coupon, and the same offset was applied to minimize bending stresses inherent in the testing of lap-shear specimens. Three coupons were tested for each parameter combination, and the average value was calculated along with the standard deviation. Image analysis was employed using an optical microscope on the fracture surfaces of lap-shear coupons to measure the load-bearing areas of the weld nugget. Areas of weld nugget that were corroded by the environmental exposure exhibited a visually darker surface due to the corrosion/oxidation oc- curring there, and this fracture surface contrast was the basis for the image analysis.

\section{Results and Discussion}

\section{Characterization of the Weld}

The macrostructure of the CMT spot weld cross section was observed by optical microscope and a representative photo is presented in Fig. 8A, the microstructure of which was much similar to the weld of 1-mm 6022-T4 aluminum alloy + 1.5-mm-thick HDG DC03. The CMT process achieves a welding-brazing joint because the welding wire and adjacent aluminum substrate melts approximately $900^{\circ} \mathrm{C}$ below the steel. Any zinc on the steel surface is melted and forms a low-melting-point eutectic with the aluminum. The molten aluminum alloy pool then wets the steel surface. Figure 8B and $C$ are photomicrographs of the weld in the notch root area and along the faying interface respectively, both of which highlight the weld microstructure and intermetallic compound (IMC) layer, which were analyzed by using a scan- 


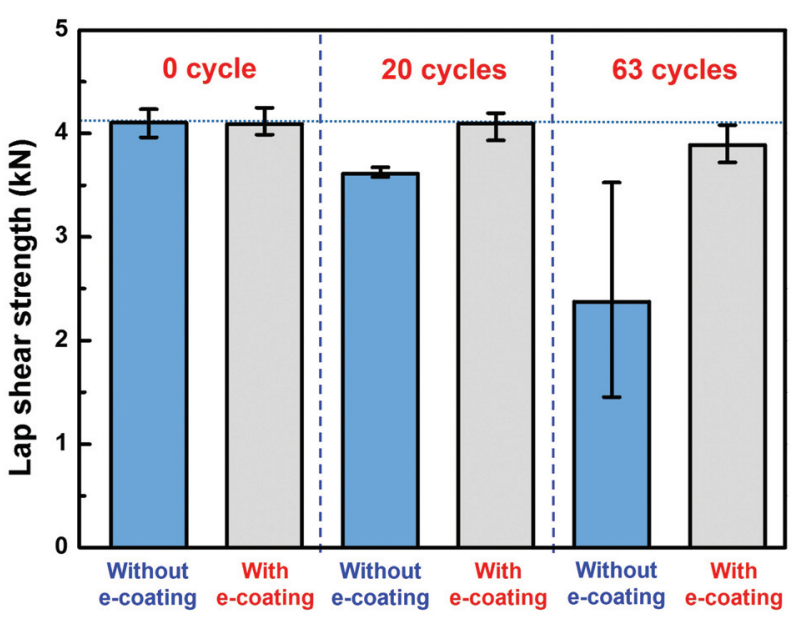

Fig. 13 - Lap shear strength of CMT Al-steel welds (with and without e-coating) measured as-welded and following environmental exposure for 20 and 63 cycles.

ning electron microscope with accompanying EDS analysis. Results are shown in Table 4.

Position 1 located at the $\mathrm{Fe}-\mathrm{Al}$ IMC layer was identified as $\mathrm{Fe}_{2} \mathrm{Al}_{5}$. Because the beam spot of EDS was too close to the steel substrate, the reflections of the Fe element were picked up from the steel. Positions 2 and 3 were the $\mathrm{Al}-\mathrm{Zn}$ mixture, indicating that a zinc-rich zone existed between the aluminum weld metal and Fe-Al IMC layer. Farther into the weld, though still along the faying interface, a thin IMC layer, i.e., $\mathrm{Fe}_{2} \mathrm{Al}_{5}$, with very little zinc was detected at position 4 .

Figure 9A is a photo of the as-welded panel, and Fig. 9B is a photo of the welded and e-coated panels, which appear black.

\section{Electrochemical Measurements}

As a measurement of the corrosion tendency for the different alloy compositions making up the Al-steel joint (refer to Fig. 5), the OCP was plotted as a function of time (refer to Fig. 10A). The majority of positions exhibit a trend of decreasing $\mathrm{OCP}$ values with time. However, for those positions ( 1 and 2) exhibiting an increase of the OCP over time, the authors attribute this to an increasing protective property of a passive $\mathrm{Al}_{\mathrm{x}} \mathrm{O}_{\mathrm{y}}$ film during the exposure to the elec- trolyte. To compare these values, an average $\mathrm{OCP}$ was calculated by averaging the values in the time frame of 1800 $3600 \mathrm{~s}$. This was done for three replicates per position, and the average $\mathrm{OCP}$ values were then plotted as a function of relative position within the joint stackup (refer to Fig. 10B).

The OCP for the zinc coating on the steel substrate was the most negative, which is similar to the bottom surface of the weld, position 7, as would be expected assuming that the surface temperature at the bottom surface of the steel does not reach the melting point of zinc during welding. The $\mathrm{OCP}$ of the Fe-Al IMC layer mixed with zinc, position 4, was also very low, about $-1.0 \mathrm{~V}$, compared with the weld metal in the aluminum side. Thus, this would drive the IMC layer to corrode after the corrosion of the zinc-rich zone. The OCP of the aluminum base alloy was relatively higher and $\mathrm{OCP}$ of the $\mathrm{Al}$ weld decreased in OCP value from the surface of the weld to the faying interface, especially positions 2 to 3 , which is attributed to a greater zinc-alloying content closer to the faying interface (refer to Fig. 10A). This can be explained by the fact that the zinc coating has a low boiling point of $906^{\circ} \mathrm{C}$, such that when it is exposed to the heat from the welding arc, it will evaporate and become trapped at the weld root.

This was detected by EPMA analysis of zinc distribution in the weld nugget, as shown in Fig. 11. The OCP of the steel substrate and positions 5 and 6 within the steel substrate were the most positive, indicating the greatest corrosion resistance. The OCP of positions 2, 3, and 4 was the result of mixed potentials.

Therefore, according to the $\mathrm{OCP}$ results, it is proposed that the zinc coating on the steel surface will corrode first during the corrosion process. However, the zinc coating on the steel in the vicinity of the weld notch root corroded slowly because of the difficulty for the electrolyte solution to penetrate into this overlapped area. Once the solution penetrated into the overlapped area and following extended exposure times, the zinc-rich zone at the weld notch root corroded and the corrosion propagated into the aluminum weld metal through the zinc distribution at the notch root. The existence of e-coating on the panels provides a barrier to the invasion of electrolyte solution into the overlapped area, and the corrosion rate is slowed, highlighting the beneficial attributes of e-coating.

\section{Macro Morphology of the Corroded Panels}

Photos exhibiting the morphologies of the welded panels with and without e-coating after salt spray exposure for different cycles are presented in Fig. 12. The uncoated welded

Table 4-Chemical Compositions of Different Points (at.-\%)

Elements

Positions

\begin{tabular}{cccccc} 
Positions & Al & Fe & Zn & Si & Phases \\
\hline 1 & 58.12 & 25.19 & 6.65 & 10.04 & $\mathrm{Fe}_{2} \mathrm{Al}_{5}$ \\
2 & 49.38 & 2.91 & 45.40 & 2.32 & $\mathrm{Al}-\mathrm{Zn} \mathrm{mixture}$ \\
3 & 59.50 & 2.42 & 36.61 & $\mathrm{Al}-\mathrm{Zn} \mathrm{mixture}$ & $\mathrm{Fe}_{2} \mathrm{Al}_{5}$ \\
4 & 64.63 & 26.12 & 0.27 & 8.98 & \\
\hline
\end{tabular}



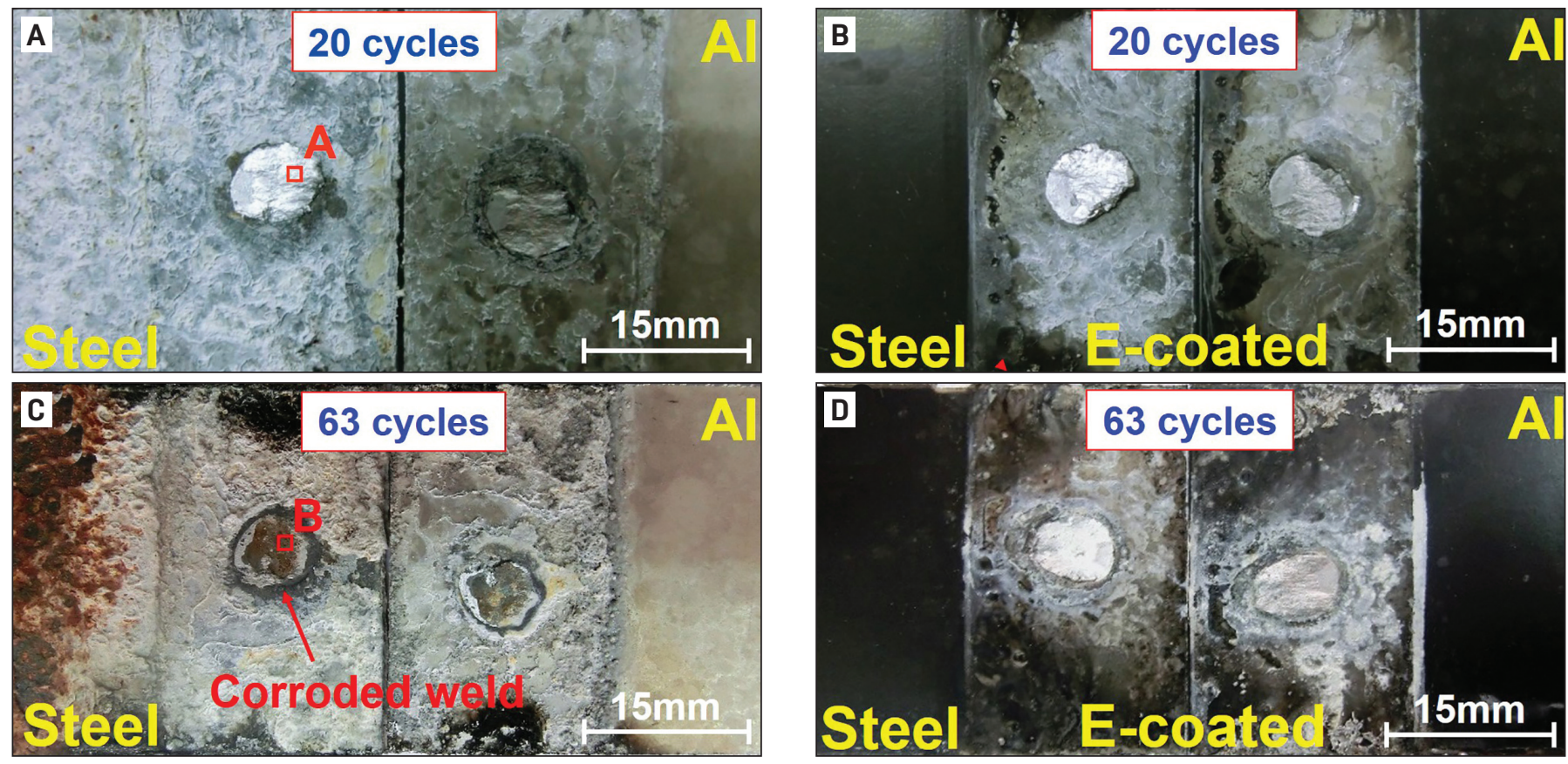

Fig. 14 - Fractography of the weld under applied load: A - Uncoated weld after 20 cycles; B - e-coated weld after 20 cycles; C - uncoated weld after 63 cycles; $D-e$-coated weld after 63 cycles.
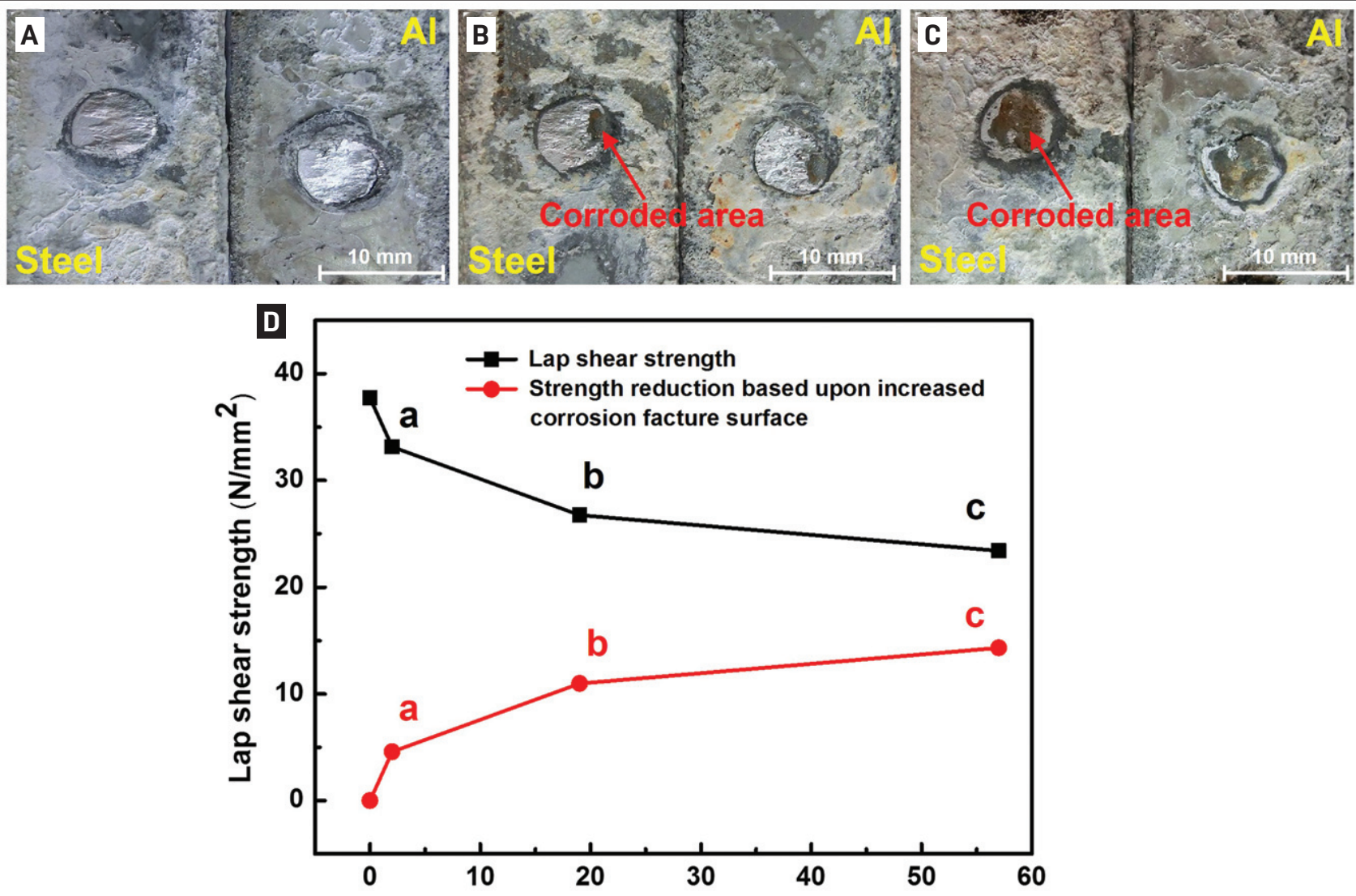

Percentage of corroded weld nugget fracture surface (\%)

Fig. 15 - Fractographies and lap-shear strengths of non e-coated coupons with a different \% of corroded weld nugget fracture surface following 63 cycles of GM74872 environmental exposure testing: A - 2.3\%; B - 18.5\%; C - 67.7\%; D - weld strength with different percentage of corrosion weld nugget fracture surface shown in $A, B$, and $C$. 

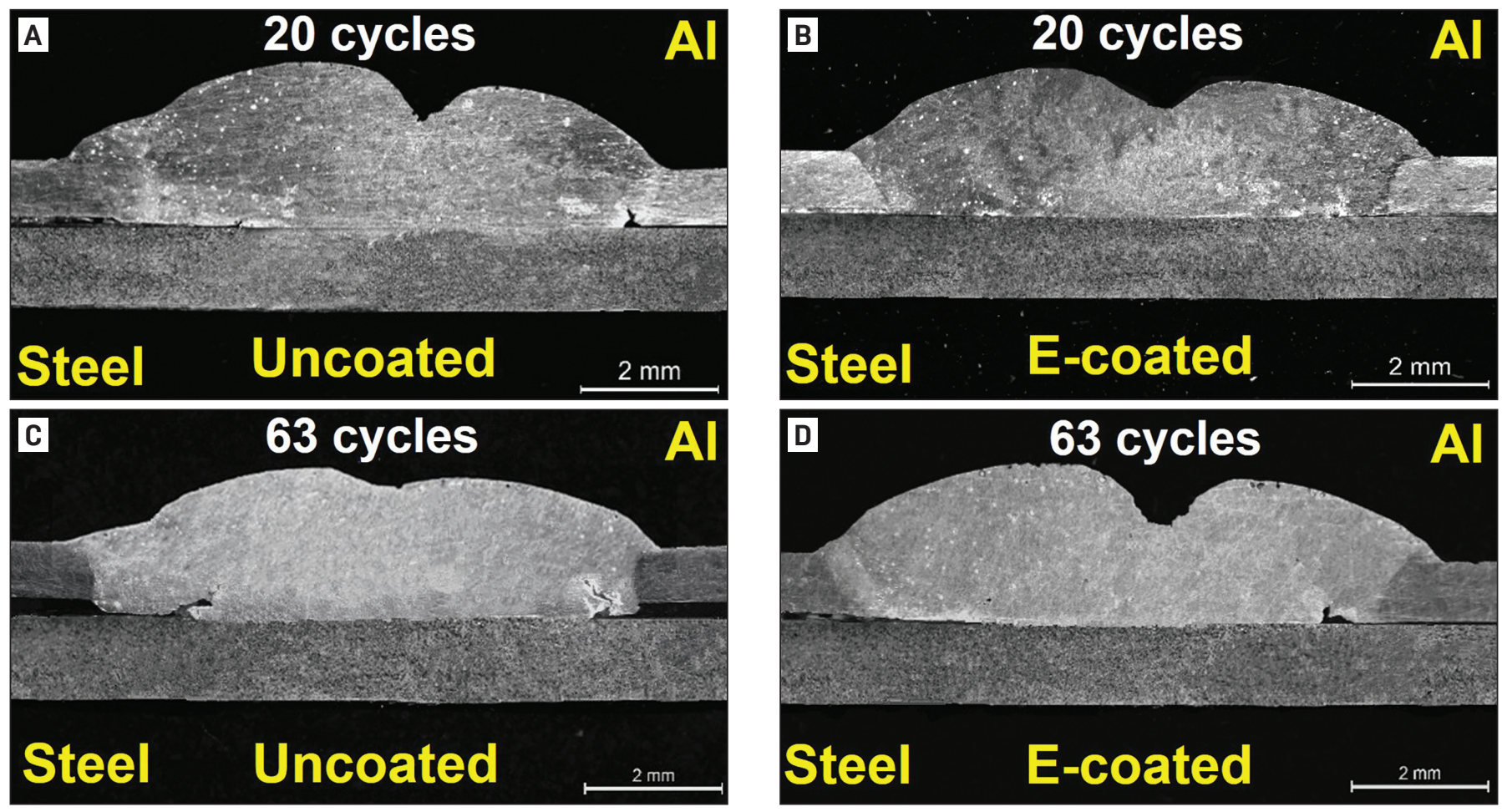

Fig. 16 - Photomicrographs of polished cross sections of the Al-steel weld following environmental exposure: A - Uncoated weld after 20 cycles; $B$-e-coated weld after 20 cycles; $C$ - uncoated weld after 63 cycles; $D$ - e-coated weld after 63 cycles.

panels exhibit a white color indicating oxidation of the zinc coating and areas of brown rust after 20 cycles of environmental exposure (refer to Fig. 12A). Brown rust can also be observed in some locations, which indicates full oxidation of the zinc coating and oxidation of the base steel substrate has begun. Conversely, the e-coated panels (refer to Fig. 12B) were well protected and no obvious corrosion was detected. The white drops on the surface in the photo are dried electrolyte solution left on the panels. After 63 cycles of environmental exposure, the uncoated steel panel exhibited severe corrosion as evidenced by a thick layer of brown rust (refer to Fig. 12C). For the same exposure, the aluminum panel exhibits a white corrosion product covering the sheet in contrast to the darker grey color of the aluminum panel seen in Fig. 12A. After 63 cycles, the e-coating was still providing corrosion protection; however, evidence of white corrosion product could be found in the vicinity of the overlapped region.

\section{Lap-Shear Strength}

For the investigation of corrosion on the mechanical property of the welds, lap-shear testing was conducted following 20 and 63 cycles of salt spray exposure. The results are summarized in Fig. 13. As a baseline, coupons were tested prior to any environmental exposure and measured a lapshear strength of approximately $4.1 \mathrm{kN}$ independent of the presence of e-coating or not.

The fracture mode was crack initiation at the weld notch root progressing into and through the weld to create a partial button similar to that presented in Fig. 14A and B. Following 20 cycles of salt spray exposure, there was no measurable effect for coupons that were e-coated. Based upon observation of a clear demarcation in Fig. 14B between the black e-coated steel surface and the oxidized steel surface in the overlap area, it was concluded that the e-coating did not penetrate fully around the welds. For those welds without e-coating, the lap strength after 20 cycles of exposure was reduced to a value of $3.6 \mathrm{kN}$, retaining the same fracture mode as the baseline - Fig. 13. Again, after 63 cycles, there was no degradation of lapshear strength for the e-coated coupons; however, for coupons without e-coating, the strength reduction was significant, measuring an average strength of $2.6 \mathrm{kN}$. Furthermore, the fracture mode changed to one of interfacial fracture along the IMC layer. This can be understood in the observation of a thick oxidation layer in the region of overlap and corrosion directly on the weld fracture surface (refer to Fig. 14C), which also caused the large fluctuation of the weld strength shown in Fig. 13. Thus, e-coating exhibits an ability to provide significant corrosion protection for coupon-level testing even without complete joint penetration into the Al-steel overlapped area (refer to Fig. 14D). Further work under conditions of durability type testing would be required to represent in-use conditions for automotive applications.

Observation of the fracture surfaces for the welds without e-coating tested after 63 cycles of environmental exposure (refer to Fig. 15A-C) led to the correlation of the \% area of weld nugget corroded during the salt spray test, i.e., extent of corrosion, to the lap-shear strength (refer to Fig. 15D). This implies that as the corrosion progresses, the bond between the $\mathrm{Al}$ and steel is destroyed, thereby reducing the overall load-bearing area of the joint. For the 

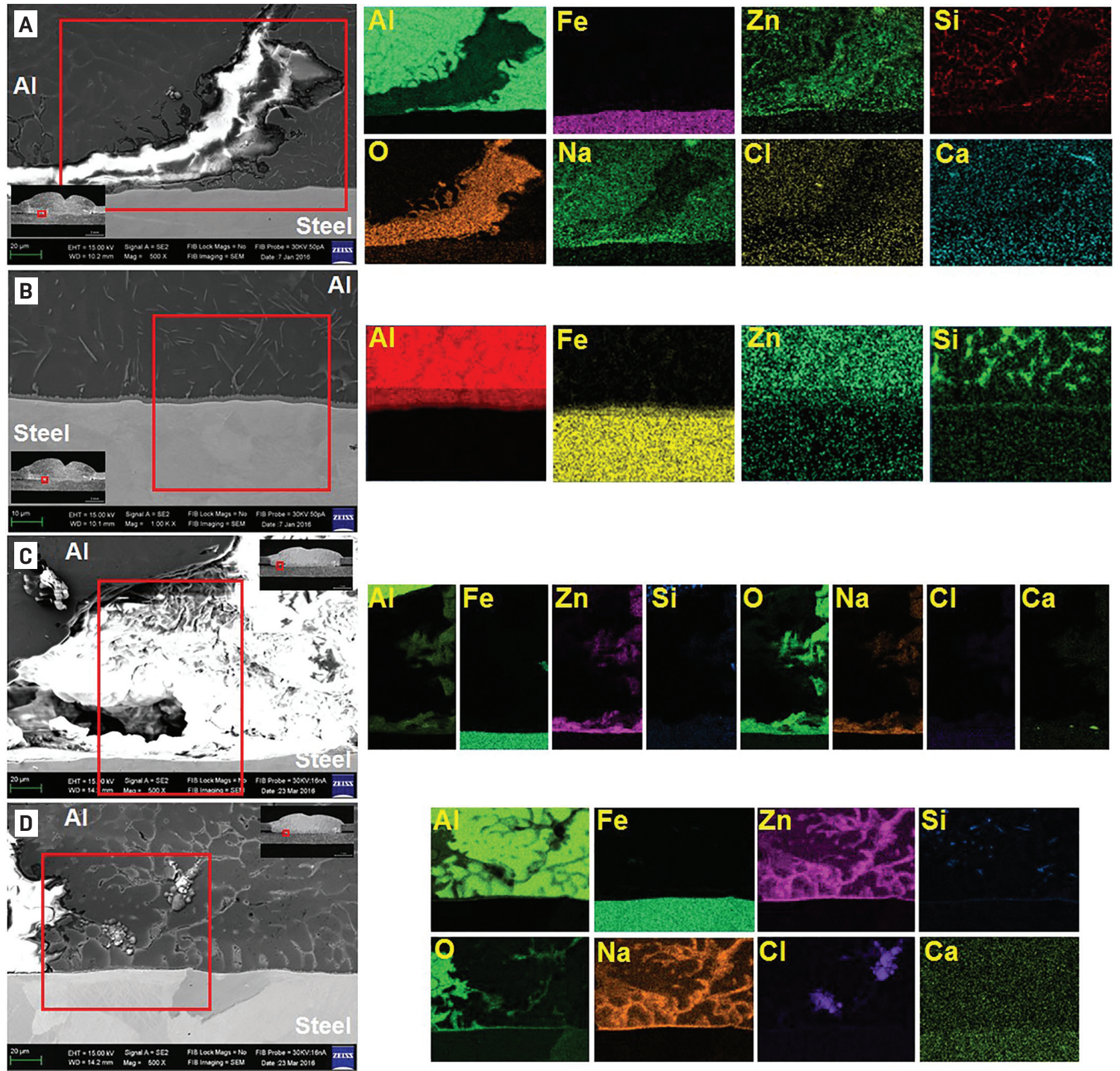

Fig. 17 - Microstructure of the corroded weld notch root without e-coating: A - Corrosion propagation in the weld notch root after 20 cycles; $B$ - IMC layer near the weld notch root without corrosion after 20 cycles; $C$ - corrosion propagation in the weld notch root after 63 cycles; D - corroded IMC layer near the weld notch root after 63 cycles.

welds shown in Fig. 15A-C, the percentage of corroded weld nugget fracture surface increased greatly from 2 to 57\% (refer to Fig. 15D) because the weld with the largest corrosion area was close to the edge of the panel, as shown in Fig. 9A and exposed much more to the corrosion solution; the weld adjacent to the panel center corroded slightly. As the percentage of the corroded weld nugget area increased to $57 \%$, corresponding to the fractography presented in Fig. 15C, the weld strength per unit area decreased from $38 \mathrm{~N} / \mathrm{mm}^{2}$ for the as-welded and e-coated condition to approximately $23 \mathrm{~N} / \mathrm{mm}^{2}$, which implies there is another mechanism beyond the load-bearing area at play. As the square of corrosion area increased, which caused a smaller load-bearing area, the reduction of the lap-shear strength also became larger simultaneously (refer to Fig. 15D), which was calculated by the lap-shear strength of the weld without corrosion subtracted by the value of the weld strength after corrosion, then divided by the area of corroded interface. This could very well have to do with the stress state at the faying interface/notch root, which requires further investigation beyond the current body of work. 

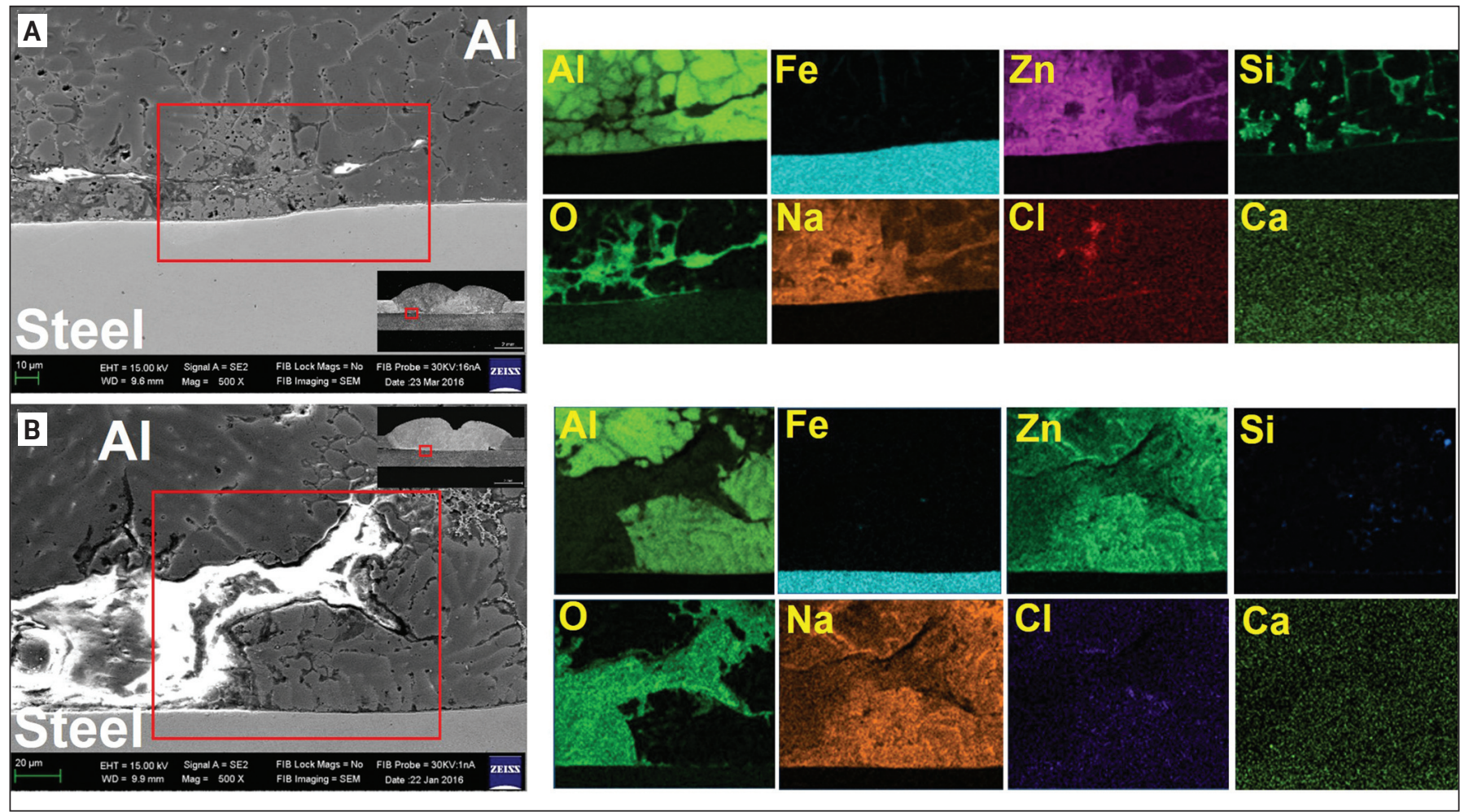

Fig. 18 - Microstructure of the corroded weld notch root for coupons having been e-coated: A - After 20 cycles; B - after 63 cycles.

\section{Macro and Microstructural Analysis of the Weld Cross Section}

To investigate the effect of environmental exposure on the macrostructure of the weld, the welds were cross sectioned, mounted, polished, and observed by optical microscope. Photomicrographs of coupons after being exposed to 20 and 63 cycles are presented in Fig. 16. After 20 cycles of salt spray exposure, the weld without e-coating (refer to Fig. 16A) exhibited corrosion, which propagated into the aluminum weld metal on both sides of the weld notch root near the boundaries of the faying interface. This can be compared with the as-welded photo in Fig. 8A. In contrast, very little corrosion was evident in the weld root for the ecoated sample after 20 cycles (refer to Fig. 16B), indicating the effectiveness of the e-coating for this duration as a barrier to the environmental exposure electrolyte between the aluminum and steel. Corrosion continued to propagate into the weld metal on the aluminum side for non e-coated coupons after 63 cycles of environmental exposure (refer to Fig. 16C). This observation correlates with the elevated zinc distribution at the weld root (refer to Fig. 11). For the e-coated sample after 63 cycles, there is a greater extent of corrosion observed (refer to Fig. 16D) than after 20 cycles, however, not nearly to the extent observed for the coupon without e-coating.

To investigate any microstructural relationship to the preferred path of corrosion, the microstructure and element distribution of the corroded weld without e-coating were captured using SEM and EDS (refer to Fig. 17). As noted previously, after 20 cycles of environmental exposure, the weld nugget root was corroded (refer to Fig. 17A).
The EDS mapping analysis confirmed that the corrosion path followed regions of elevated zinc content along the faying interface and then into the zinc-rich region of the weld metal. The IMC layer farther along the faying interface near the weld centerline exhibited no corrosion (refer to Fig. 17B). After 63 cycles of environmental exposure, which can be seen in Fig. 17C, large amounts of aluminum weld metal dissolved with significant zinc corrosion at the weld notch root. The IMC layer mixed with the zinc element near the notch along the interface between the aluminum weld metal, and the steel substrate was also oxidized (refer to Fig. 17D). High levels of $\mathrm{Na}$ and $\mathrm{Cl}$ were measured indicating salt residue. Therefore, the weld strength and the area of bearing load decreased significantly, and the fracture mode turned to interfacial fracture, as shown in Figs. 13 and 14C.

To study the effect of e-coating on the corrosion process of the dissimilar material welds, the cross section of the ecoated weld after salt spray exposure was also analyzed with SEM and EDS, and the results are presented in Fig. 18. After 20 cycles of exposure, the zinc-rich zone at the notch root exhibited slight oxidation (refer to Fig. 18A), which was significantly less compared to the weld having no ecoating, compare to Fig. 17A. Na and $\mathrm{Cl}$, which are indicative of the electrolyte, were also detected around the weld root, indicating the coating could not seal the overlapped area entirely. The corrosion at the weld notch root after 63 cycles propagated into the aluminum weld root in the zincrich region, as shown in Fig. 18B; however, the extent of corrosion was also less severe in contrast to the weld having no e-coating, indicating the coating provided a partial block to the electrolyte solution attacking the weld root. 

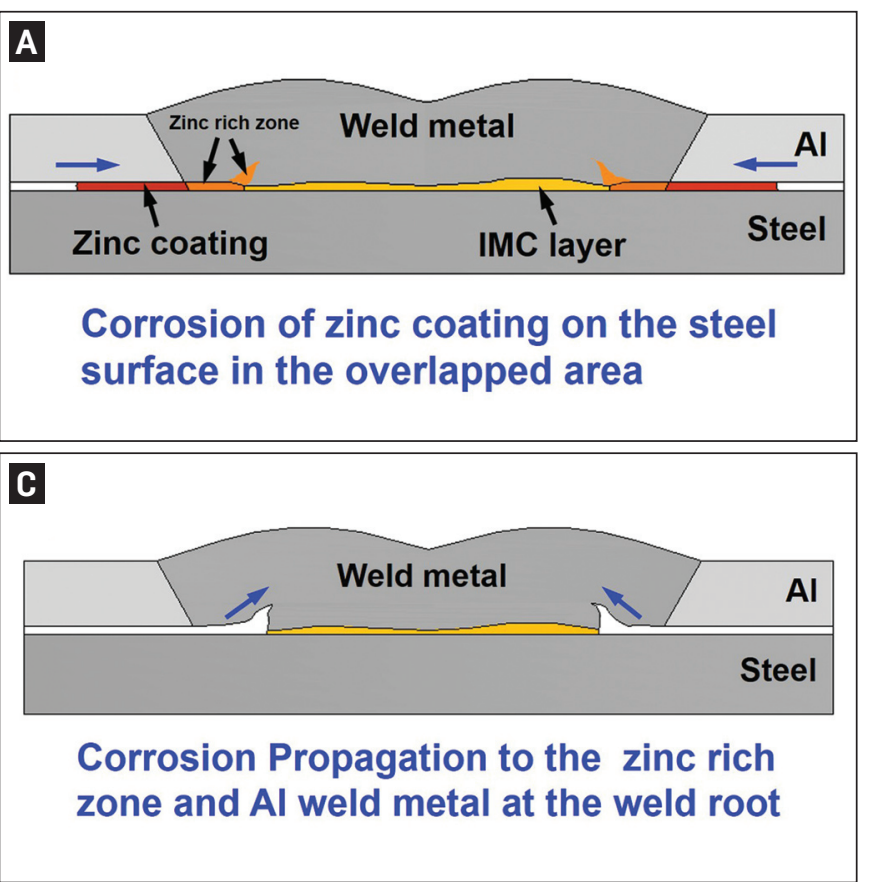

B

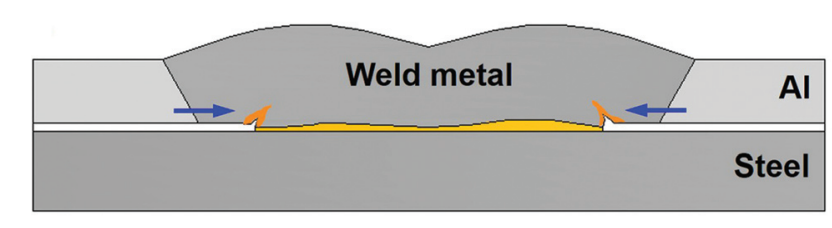

Corrosion of zinc rich zone at the weld root

D

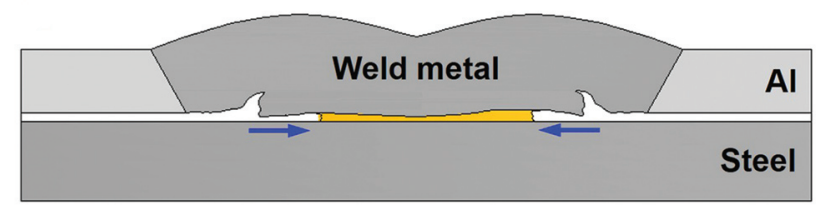

Corrosion Propagation to the Fe-AI IMC layer

Fig. 19 - Corrosion mechanism of Al and steel CMT spot weld: A - Corrosion of zinc coating on the steel surface; B - corrosion of the zinc-rich zone at the weld notch root; $C$ - corrosion propagation in the zinc-rich zone of the weld notch root; $D-$ corrosion propagation in the IMC layer.

\section{Corrosion Mechanism}

To explain the corrosion mechanism observed in the CMT arc spot welded Al-steel coupons following environmental exposure, the following model (refer to Fig. 19) is put forth. For corrosion to occur, the electrolyte solution must penetrate between the $\mathrm{Al}$ and steel sheets into the overlapped area. The zinc coating on the steel surface has the lowest open circuit potential and, as such, preferentially corrodes (refer to Fig. 19A). As the zinc coating is corroded along the steel surface, the solution attacks the zinc-rich zone of the weld notch root, which begins to corrode as shown in Figs. 19B and 17A. As the number of cycles and corresponding exposure time increases, the corrosion continues propagation into the weld metal along a path of zinc-rich microstructure (refer to Figs. 19C, 11, and 17C). As the zinc-rich material is being corroded, so too is the aluminum weld metal oxidized. Once the corrosion has propagated through the zinc-rich zone, the Fe-Al IMC layer mixed with zinc coating, which evaporated from the steel surface during welding, is preferentially corroded, thereby reducing the load-bearing joint between the $\mathrm{Al}$ and steel (refer to Figs. 19D and 17D). This results in a decrease of the lap-shear strength and transition of fracture mode to interfacial fracture (refer to Fig. 14C). The following anodic and cathodic reactions of the various stages corresponding to Fig. 19A-D are presented:

Anodic reaction:
(a) $\mathrm{Zn} \rightarrow 2 \mathrm{e}^{-}+\mathrm{Zn}^{2+}$
(b) $\mathrm{Zn} \rightarrow 2 \mathrm{e}^{-}+\mathrm{Zn}^{2+}$
(c) $\mathrm{Zn} \rightarrow 2 \mathrm{e}^{-}+\mathrm{Zn}^{2+}$, $\mathrm{Al} \rightarrow 3 \mathrm{e}^{-}+\mathrm{Al}^{3+}$
(d) $\mathrm{Zn} \rightarrow 2 \mathrm{e}^{-}+\mathrm{Zn}^{2+}$,

$$
\begin{aligned}
& \mathrm{Al} \rightarrow 3 \mathrm{e}^{-}+\mathrm{Al}^{3+}, \mathrm{Fe} \rightarrow 2 \mathrm{e}^{-}+\mathrm{Fe}^{2+} \\
& \mathrm{O}_{2}+2 \mathrm{H}_{2} \mathrm{O}+4 \mathrm{e}^{-} \rightarrow 4 \mathrm{OH}^{-}
\end{aligned}
$$

Cathodic reaction:

\section{Conclusions}

The corrosion properties of CMT spot-welded 1-mmthick AA6022-T4 to 1.5-mm-thick HDG DC03 welds were investigated. The OCP of base materials and different portions of the welds from top to bottom were measured, and salt spray exposure testing was conducted for the welds with and without e-coating for durations of 20 and $63 \mathrm{cy}$ cles. After exposure, the welds were investigated and compared in terms of joint morphology, mechanical properties, as well as macro- and microstructure. The following conclusions can be drawn:

1) The OCP value differed between the weld and base metals and varied as a function of position within the weld. The OCP of the zinc coating on the steel substrate was the most negative, which was similar to the bottom surface of the weld. The OCP of the Fe-Al IMC layer in the interface mixed with zinc was also very low. The OCP of the aluminum weld metal was relatively higher and decreased from the surface of the weld to the faying interface due to the mixed zinc vapor during the welding process. The OCP of the steel substrate was the most positive, indicating the strongest corrosion resistance.

2) During salt spray tests, the electrolyte solution penetrated along the opening between the welded $\mathrm{Al}$ and steel sheets, migrating toward the weld notch root. The zinc coating on the steel surface has the largest negative electrochemical potential and would corrode first. Then as the elec- 
trolyte penetrates, it would attack the zinc-rich zone at the weld notch root.

3) Considering the as-welded condition as the baseline lapshear strength with a nugget pullout through the $\mathrm{Al}$ as the fracture mode, the average strength dropped $12 \%$ following 20 cycles of salt spray exposure and $41 \%$ following 63 cycles coupled with a change in fracture mode to interfacial.

4) E-coating has a very positive effect upon corrosion of the CMT Al-steel welds. The e-coating provides a barrier to the penetration of the electrolyte solution into the overlapped area between the top and bottom sheets. Resulting lap-shear strengths exhibited no statistical difference between the aswelded and post-environmentally exposed conditions.

\section{Acknowledgments}

The authors would like to acknowledge the support of GM Research and Development Center and National Natural Science Foundation of China (Grant Nos. U1564204, U1764251, and 51322504).

\section{References}

1. Qiu, R., Iwamoto, C., and Satonaka, S. 2009. Interfacial microstructure and strength of steel/aluminum alloy joints welded by resistance spot welding with cover plate. Journal of Materials Processing Technology 209(8): 4186-4193.

2. Sun, X., Stephens, E. V., Khaleel, M. A., Shao, H., and Kimchi, M. 2004. Resistance spot welding of aluminum alloy to steel with transition material - From process to performance - Part I: Experimental study. Welding Journal 83(6): 188-s to 195-s.

3. Watanabe, T., Takayama, H., and Yanagisawa, A. 2006. Joining of aluminum alloy to steel by friction stir welding. Journal of
Materials Processing Technology 178: 342-349.

4. Wan, Z., Wang, H.-P., Chen, N., Wang, M., and Carlson, B. E. 2017. Characterization of intermetallic compound at the interfaces of Al-steel resistance spot welds. Journal of Materials Processing Technology 242: 12-23.

5. He, X., Pearson, I., and Young, K. 2008. Self-pierce riveting for sheet materials: State of the art. Journal of Materials Processing Technology 199(1-3): 27-36.

6. Zhang, H. T., Feng, J. C., and He, P. 2013. Interfacial phenomena of cold metal transfer (CMT) welding of zinc coated steel and wrought aluminum. Materials Science and Technology 24(11): 1346-1349.

7. Zhang, H. T., et al. 2009. The arc characteristics and metal transfer behavior of cold metal transfer and its use in joining aluminum to zinc-coated steel. Materials Science and Engineering: A 499(1-2): 111-113.

8. Lei, H., et al. 2015. Cold metal transfer spot joining of AA6061-T6 to galvanized DP590 under different modes. Transactions of the ASME. Journal of Manufacturing Science and Engineering 137(5): 051028.

9. Lei, H., et al. 2016. Microstructure and mechanical performance of cold metal transfer spot joints of AA6061-T6 to galvanized DP590 using edge plug welding mode. Transactions of the ASME. Journal of Manufacturing Science and Engineering 138(7): 071009.

10. Wloka, J., et al. 2007. Corrosion properties of laser beam joints of aluminum with zinc-coated steel. Corrosion Science 49(11): 4243-4258.

11. Shi, Y., et al. 2016. Corrosion behavior of aluminum-steel weld-brazing joint. Journal of Materials Engineering and Performance 25(5): 1916-1923.

12. Davis, J. R. 2006. Corrosion of Weldments. ASM International, Materials Park, Ohio.

13. Miyamoto, K., Nakagawa, S., Sugi, C., Sakurai, H., et al. 2009. Dissimilar joining of aluminum alloy and steel by resistance spot welding. SAE International Journal of Materials and Manufacturing 2(1): 58-67.

14. GMW14872, Cyclic Corrosion Laboratory Test. 2006. General Motors Corp., USA.

HAIYANG LEI and YONGBING LI (yongbinglee@sjtu.edu.cn) are with the State Key Laboratory of Mechanical System and Vibration, Shanghai Key Laboratory of Digital Manufacture for Thin-walled Structures, School of Mechanical Engineering, Shanghai Jiao Tong University, Shanghai, China. YANG GUO is with the Advanced Materials Lab, General Motors China Advanced Technical Center, Pudong, Shanghai, China. BLAIR E. CARLSON is with the Manufacturing Systems Research Lab, General Motors Research \& Development Center, Warren, Mich. 